\title{
Ciclopirox Olamine Lotion
}

National Cancer Institute

\section{Source}

National Cancer Institute. Ciclopirox Olamine Lotion. NCI Thesaurus. Code C92171.

A lotion preparation of the olamine salt of ciclopirox, a synthetic hydroxypyridone derivative with broad-spectrum antifung al and anti-inflammatory activities. Although its mechanism of action is not well understood, ciclopirox may chelate trivalent cations, such as Fe3+ and $\mathrm{Al} 3+$, thereby inhibiting the availability of essential metal co-factors for enzymes, which may result in a loss of enzyme activities that are essential for cellular metabolism, organization of cell wall structure, and other crucial cell functions in a wide variety of fungal species. This agent may also disrupt DNA repair, cell division signals and mitotic spindles as well as some elements of intracellular transport in susceptible fungi. Ciclopirox exhibits anti-inflammatory activity by inhibiting 5-lipoxygenase and cyclooxygenase (COX). 